\title{
Back to the Debate: Sternalis Muscle
}

\author{
Volver al Debate: Músculo Esternal \\ Laurie Y. Hung; Octavian C. Lucaciu \& Jessica J. Wong
}

HUNG, L. Y.; LUCACIU, O. C. \& WONG, J. J. Back to the debate: sternalis muscle. Int. J. Morphol., 30(1):330-336, 2012.

SUMMARY: The sternalis muscle (SM) is an anatomical variant found in the anterior thoracic wall. While the attachment sites of SM are generally agreed upon, the innervation and function of this muscle are not well established. Cadaveric and surgical explorations to date report that SM is innervated by either the pectoral nerves or the anterior branches of the intercostal nerves, or a combination of both. Knowledge of SM is relevant to health care providers specialising in imaging and/or surgery of the anterior thoracic wall. This paper aims to raise awareness in the medical community of the clinical relevance of SM through two case reports and a brief literature review.

KEY WORDS: Pectoralis muscles; Rachischisis; Pectoral nerves; Intercostal nerves.

\section{INTRODUCTION}

The sternalis muscle (SM) is an anatomical variant found in the anterior thoracic region with a reported general incidence of approximately 3-8\% of the population (Perez et al., 2008). SM is most frequently reported as an incidental finding during routine anatomical dissection, making an interesting surprise. Although this variant muscle has been described by anatomists as early as 1867 , the anatomical and functional descriptions of this muscle are not well established (Turner, 1867). While there is a general agreement amongst scholars regarding SM attachment sites, the innervation and function of this muscle remains an area of debate. Cadaveric and surgical studies to date report that SM is innervated by either the pectoral nerves (Kida et al., 2000) or the anterior branches of the intercostal nerves (Sarikçıglu et al., 2008), or a combination of both (O'Neill $\&$ Folan-Curran, 1998). The challenge in identifying the presence of SM in vivo has limited the ability of anatomists to establish the function of this muscle. Knowledge of SM is relevant to health care providers dealing with surgery of the anterior thoracic wall, oncology (particularly breast cancer), and diagnostic imaging of the anterior thoracic wall. It is important that physicians are aware of SM as this will aid in diagnosis, prevent misdiagnosis, and help direct surgery. This paper aims to raise awareness in the medical community of the clinical relevance of SM through two case reports and a brief literature review.

\section{CASE REPORTS}

Case 1. An aborted female fetus at approximately 20 weeks of development (Note: therapeutic abortion took place due to a lumbosacral rachischisis, ultrasonographically diagnosed) was examined by dissection (Fig. 1). Upon superficial examination of the anterior thoracic wall of the fetus, a right breast mass was revealed. After removing the skin, a unilateral sternalis muscle was found superficial to the thoracic fibers of pectoralis major, coursing along the right sternal border. The muscle was flat and triangular in shape, with its base situated distally, and its muscle fibers running in a cranio-caudal direction. It attached proximally to the manubrium sternalis via a long and thick tendon. The distal attachment was along the superior border of the 5th costo-cartilage. This part of the muscle was covered by the pectoralis tertius muscle, which represented a secondary muscle variant of this case. After resecting SM's tendon and reflecting it inferiorly, an incomplete development of the sternocostal head of pectoralis major was observed. The nerve supply to the muscle was visualized by direct macroscopic observation of the specimen. The medial pectoral nerve (MPN) innervated the pectoralis minor and major muscles; then coursed through the substance of the sternocostal part of pectoralis major to course medially toward the deep surface of SM, supplying SM. The lateral pectoral nerve had the typical course of supplying the clavicular head of pectoralis 
major, and did not appear to pierce pectoralis major or to send branches to SM. The anterior cutaneous branches of the 2nd, 3rd and 4th intercostal nerves hooked around the medial border of SM to supply the skin of the anterior thoracic wall parasternally. Macroscopically, the intercostal nerves did not appear to send branches to SM. We did not encounter anterior cutaneous branches originating from the first intercostal nerve. The anterior cutaneous branches of the 5th intercostal nerve were not affected by the presence of SM and followed a regular course.
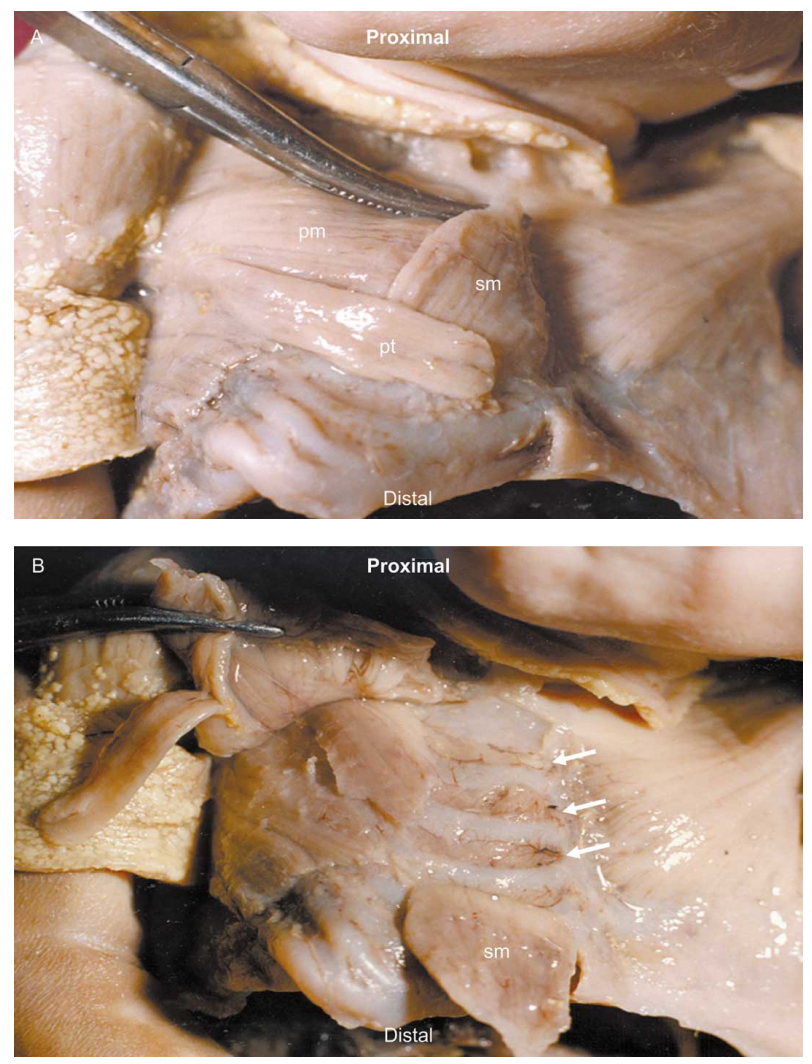

Fig. 1. Sternalis Muscle in 20 week old fetus A) Sternalis Muscle and Pectoralis tertius B) Pectoralis major reflected superolaterally, Sternalis muscle reflected inferiorly $\mathrm{pm}-$ pectoralis major, $\mathrm{pt}$ - pectoralis tertius, $\mathrm{sm}$ - sternalis muscle, arrows - anterior branches of 2 nd to 4 th intercostal nerves (cut) winding around the medial border of sternalis (reflected caudally).

Case 2. An 83-year-old female cadaver was examined by dissection. After removing the skin from the anterior thoracic wall of the 2nd specimen, a bilateral sternalis muscle was revealed, coursing along the left and right sternal borders just superficial to the pectoral fascia. Both SMs were located within a sternalis sheath, located within the pectoral fascia (Fig. 2).
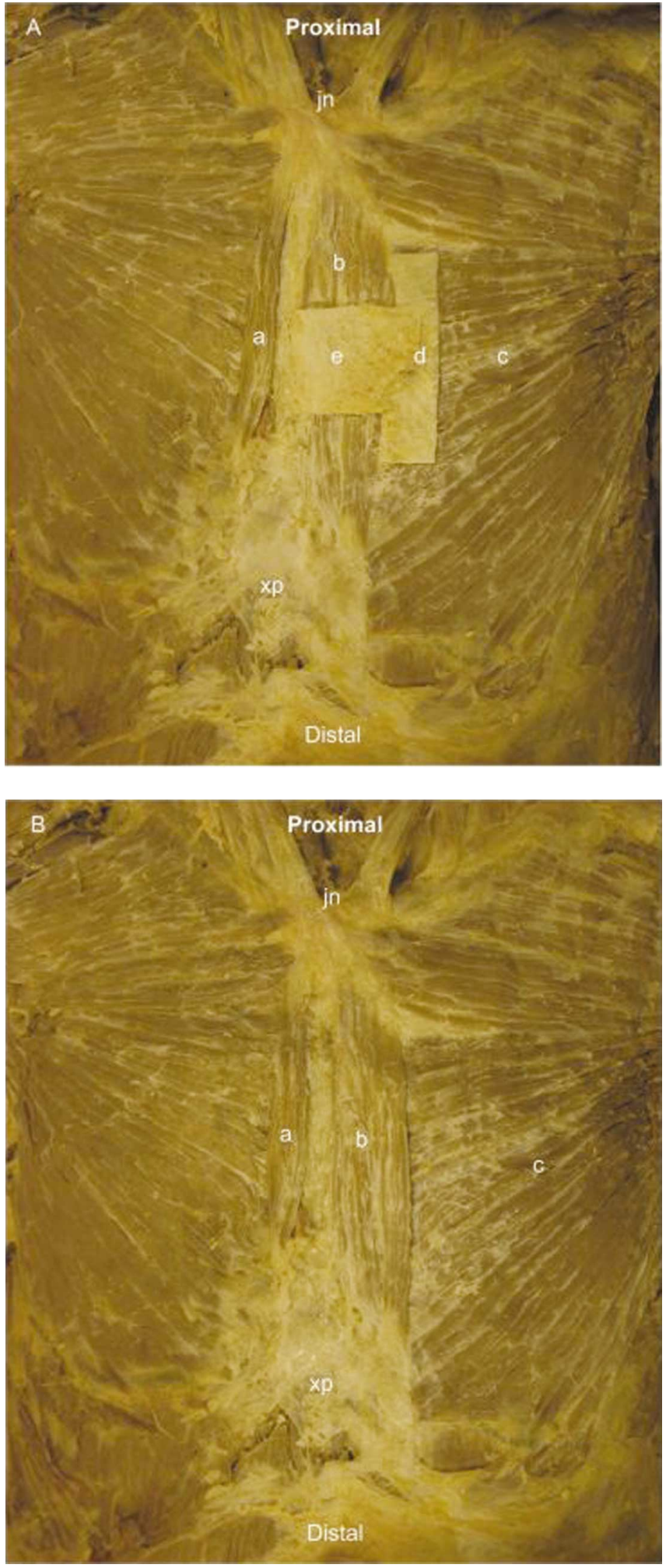

Fig. 2. Sternalis Muscle in 83 year old Female A) Sternalis muscle within a sternalis sheath B) Sternalis muscle with sternalis sheath removed jn - jugular notch, $\mathrm{xp}$ - xiphoid process, $\mathrm{a}$ - right sternalis muscle, $\mathrm{b}$ - left sternalis muscle, $\mathrm{c}$ - pectoralis major, $\mathrm{d}$ - pectoral fascia, e - sternalis sheath. 

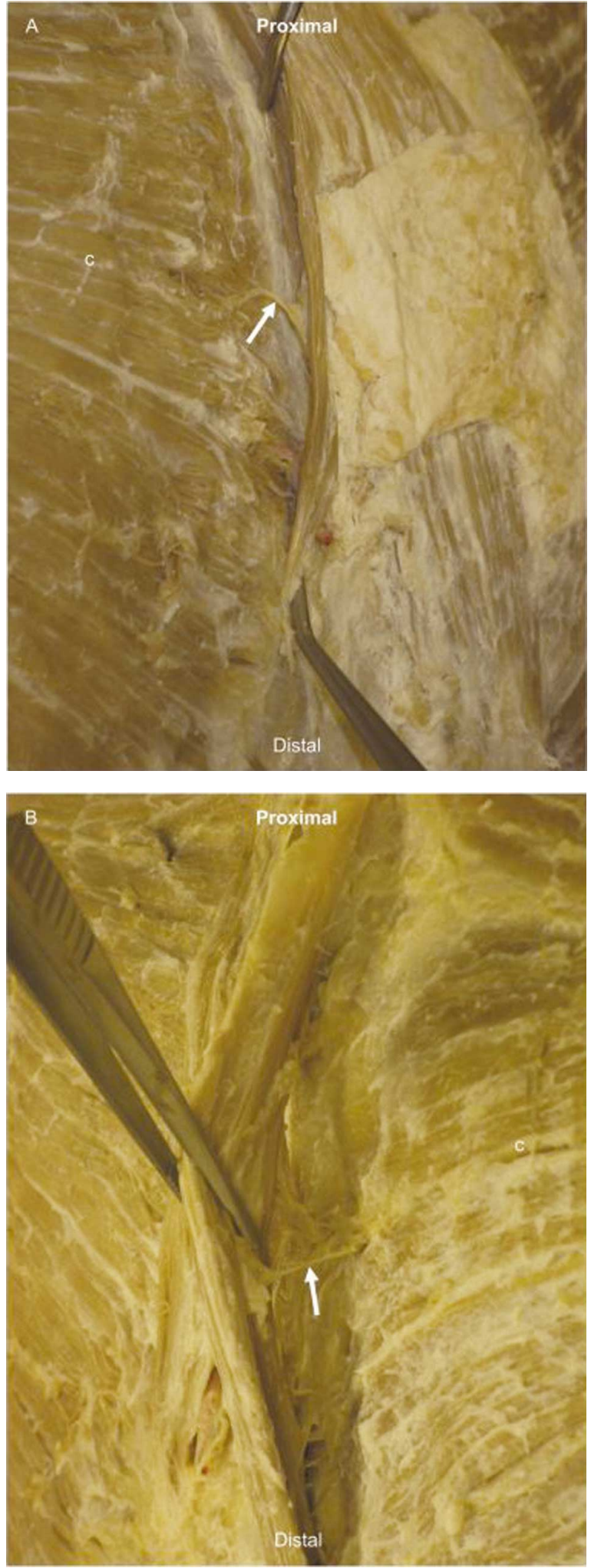

Fig. 3. Deep dissection of sternalis muscle in 83 year old female showing the (A) Right and (B) Left sternalis muscle innervation. $\mathrm{c}$ - pectoralis major; arrow (in A and B) - anterior branch of 2 nd intercostal nerve.
The transverse diameter of the left muscle belly was double the size of the right SM. The muscle was flat, strap-like in shape, with its fibers running in a cranio-caudal direction bilaterally. It attached proximally to the manubrium sternalis bilaterally via a flattened tendon bilaterally. The distal attachment of the right SM was into the pectoral fascia at the level of the 4th and 5th costal cartilages. The distal attachment of the left SM was into the pectoral fascia at the level of the 5th and 6th costal cartilages. The nerve supply to the muscle was visualized by direct macroscopic observation after deep dissection of the SMs. Both muscles were supplied by the anterior branch of the 2 nd intercostal nerve on their respective sides (Fig. 3).

\section{DISCUSSION}

The relatively large quantity of literature dedicated to SM (a search performed on PUBMED retrieved 44 articles published between 1867 and 2009) depicts this muscle as one of the most well known variant muscles in the human body. Prominent anatomists of the 19th century contributed much to the anatomical knowledge of SM (According to Turner, SM was first observed and described by Cabrolius), though interest in the muscle dwindled until the late 20th century (Turner; Shepperd, 1885; Wallace, 1886; Cunningham, 1888; Windle, 1893). The recent surge in attention to the muscle has likely been driven by advancements in soft tissue imaging together with a lack of coverage of SM in medical education curricula. Despite the large range of publication dates, the questions raised by these articles have not changed (namely the innervation and function of SM).

Anatomy. SM is generally presented as a uni- or bilateral muscle located in the anterior thoracic wall between the superficial fascia of the anterior thoracic region and the pectoral fascia, with its muscle fibers running parallel to the sternum. Variable attachment sites have been reported, although generally SM is described as inserting proximally at the manubrium sterni and distally to the 5th and 6th costal cartilages, aponeurosis of the external oblique abdominis muscle, and the sheath of the rectus abdominis (Jelev et al., 2001). Jelev et al. created a classification system to categorize different morphologies of SM, based primarily on unilateral (type I) or bilateral disposition (type II). There are 4 sub classifications under each type, based on the number and symmetry of muscle bellies, and relationship with other muscles. According to this system, the SM in case report 1 is classified as type I1 and the SM in case report 2 is classified as type II2.

While the attachment sites and presentation of SM are generally agreed upon, the innervation and embryological origin of the muscle remain topics of debate. Nerve supply to SM is commonly reported as coming from the pectoral nerves (medial 
or lateral pectoral) (Wallace; Lamont, 1887; Cunningham; Patten, 1934; Harper, 1936; Kida et al., 2000; Kumar et al., 2003) or anterior cutaneous branches of the intercostal nerves (Shepperd, 1889; Shen et al., 1992; Jeng \& Su, 1998; O’Neill \& Folan-Curran; Jelev et al.; Saeed et al., 2002; ArraezAybar et al., 2003; Motabagani et al., 2004; Gupta \& Harjeet, 2004; Sarikçıoglu et al.). According to Barlow (1935), a literature review of $146 \mathrm{SM}$ cases, reported by 17 authors, found that SM is supplied by the pectoral nerves in $68.5 \%$ of cases, intercostal nerves in $26.7 \%$, and a combination of the two in $4.8 \%$. In a literature review spanning 191 SM cases reported by 34 authors, O'Neill \& Folan-Curran found SM to be supplied by pectoral nerves in $55 \%$ of cases, by intercostals in $43 \%$, and a combination of the two in $2 \%$ of cases. Kida et al. (2000) and Loukas et al. (2004) have suggested that the delicate and fine nature of the branches of the pectoral and intercostal nerves make them difficult to dissect due a to their susceptibility to being damaged, misidentified as connective tissue, or overlooked. These factors lead to difficulty in tracing their potential innervation to SM.

Based on attachment sites and innervation of SM, several theories regarding the embryological origin of SM have been proposed. The main theories propose that SM: 1) is a cranial extension of rectus abdominis, 2) is a caudal continuation of sternomastoid, 3) is a bridging between sternomastoid superiorly and external oblique inferiorly, 4) develops from the pectoral mass from fibers that were displaced at about a right angle from the fibers of pectoralis major and minor, 5) is a remnant of panniculus carnosus, and 6) is a muscle atavistic to humans (Humphry, 1873; Barlow; Kida et al., 2000). None of these theories entirely account for the occurrence of SM. Accordingly, many terms are used in reference to SM, including rectus sternalis, thoracicus, sternalis brutorum (Turner; Loukas et al.), and presternalis (Turner; Saeed et al., 2002; Loukas et al.). The innervation and relationship with pectoralis major found in our first case report support the theory of SM originating from pectoralis major. The innervation found in our second case report supports the theory of SM originating from rectus abdominis.

The motor function of SM has not been established and has been the subject of speculation by several authors. Based on its general proximal and distal attachments, it has been hypothesized that the function may be elevation of the lower rib cage, acting as an accessory inspiratory muscle. Kirk (1925) reported the observation of a SM in a living man, where the muscle appeared to contract with active trunk flexion and arm adduction. Recently, Zaher et al. (2009) suggested that SM may have a proprioceptive function, detecting movements of the anterior thoracic wall. Our literature review did not retrieve any histological studies with regards to muscle spindles in SM.

Epidemiology. The general incidence of SM reported by authors is $3-8 \%$, but varies significantly between races (Arraez-Aybar et al., 2003; Pérez et al.). Reported incidence of SM ranges from $2.3 \%$ (Turner) to $6.4 \%$ (Barlow) in Europeans, from $1 \%$ (Jeng \& Su) to $13.1 \%$ (Barlow) in Asiatic populations, and is approximately $11 \%$ in African populations (Barlow). The incidence of SM between genders has been reported by some authors to be identical (Barlow), while others have reported a slightly higher frequency in females $(8.7 \%)$ than in males $(6.4 \%)$ (Scott-Conner \& AlJurf, 2002). This difference between genders may be confounded by the higher rates of medical imaging and surgery of the anterior thoracic wall for breast-related conditions in females than in males.

SM has been reported to present with equal frequency in a right sided or left sided asymmetric form or symmetric (bilateral) form; while unilateral muscles occur approximately twice as frequently as bilateral muscles (Bailey \& Tzarnas, 1999).

SM is associated with anomalies (usually axial) and abnormalities of pectoralis major. Shepperd $(1885,1889)$ observed SM in 9 anencephalous foetuses, 7 of which had spina bifida, 1 with a cleft palate, and 6 with the sternocostal part of pectoralis major underdeveloped. Harper reported 3 female foetuses presenting with SM, all 3 with spina bifida, 2 with anencephaly, and 1 with an underdeveloped sternocostal part of pectoralis major. The association of SM with axial anomalies such as spina bifida occulta is difficult to explain, as it would require a mechanism accounting for both the spina bifida in the lumbosacral area and disruption of the migration of the myomeric mass in the pectoral region. O'Neill \& Folan-Curran described 'pectoral slips', presenting with a SM as variations of either the chondroepitrochlearis or the pectoralis quartus. Kida \& Kudoh (1991) also described an incomplete development of the sternocostal head of the pectoralis major, as was seen in our case. The presence of SM is also associated with anomalies of the skull and adrenal gland (Harish \& Gopinath, 2003). The incidence of SM in anencephaly is nearly 50\% (Windle), however this may be confounded by the difficulty in observing SM in living humans other than by surgery or soft tissue imaging.

Clinical Application. The more recent publications concerning SM commonly discuss the muscle in the context of investigational (ex. mammography, magnetic resonance imaging) and/or surgical procedures (ex. mastectomy) of the anterior thoracic wall. Most clinically oriented papers 
emphasize the importance of and need for increased awareness of SM (Rahman et al., 2009).

Advancements in soft tissue imaging and its routine use have led to more frequent discoveries of SM in living humans (as opposed to anatomical dissection). SM has been discovered on mammography, magnetic resonance imaging (MRI), and computed tomography (CT). Bradley et al. (1996) found 4 cases out of an estimated 32000 mammograms that gave signals at the position of SM while Goktan et al. (2006) and Nuthakki et al. (2007) identified SM cases using mammography and MRI. Young Lee et al. (2006) encountered 86 cases out of 1387 CT chest scans where $7.3 \%$ of the cases were female, and $5.3 \%$ were male. It has been noted by several authors that SM may mimic carcinoma on imaging and that proper identification of SM as a benign variant muscle prevents unnecessary exploratory surgery (Kumar et al.; Pojcharmarnwiputh et al., 2007).

Discoveries of SM also occur relatively frequently during breast surgery, where an unexpected SM can be quite surprising and/or confusing. Authors describe these discoveries as a 'normal finding during breast surgery' or 'not of clinical concern' and note the importance of knowledge of the craniocaudally oriented strap of muscle (Bailey \& Tzarnas; Vandeweyer, 1999; Harish \& Gopinath). Bailey \& Tzarnas encountered 3 patients with SM undergoing mastectomy over a 15 year period, while Harish \& Gopinath found SM in 8 out of 1152 patients undergoing radical mastectomy. Some authors suggest other clinical implications of SM pertaining to breast cancer and surgery. Kabay et al. (2005) suggests that SM should be removed with the breast tissue in radical mastectomy in some breast carcinomas due to its close proximity. Other surgeons have begun using SM after mastectomy as a tissue expander material for breast reconstruction as the function of SM remains unknown (Schulman \& Chun, 2005). With regards to breast augmentation, Khan (2008) suggested that SM may interfere with the submuscular pocket dissection when an intraalveolar or submammary approach is used.

Education. While older anatomy textbooks such as Cunningham's Textbook of Anatomy and Morris' Treatise on Anatomy give detailed descriptions of SM (Davis-Colley, 1907; Lockhart, 1953), the muscle is presented only briefly in currently used textbooks such as Netter, Gray's Anatomy (as the rectus sternalis), and in Larsen's Human Embryology, and is not described at all in Clinically Oriented Anatomy (Salmons, 1995; Larsen, 1997; Saeed et al.). The absence of SM in modern texts may have influenced its lack of emphasis in medical curricula, as was reflected in a survey by Bailey \& Tzarnas that found an extremely low awareness amongst physicians and students of the existence of SM. In light of the relatively recent advanced imaging and surgical techniques, incorporation of SM into medical education curricula and re-introduction of SM into anatomy texts appears valuable as it will increase awareness of SM and allow for its proper identification to prevent misdiagnosis and allow for appropriate surgical planning (Scott-Conner \& Al-Jurf).

\section{CONCLUSION}

Two cases of SM were presented in this paper. The first case was of a highly deformed fetus with multiple anomalies, namely a SM, pectoralis tertius, incomplete development of sternocostal part of pectoralis major, and lumbosacral rachischisis. In this case, its relationship with pectoralis major and innervation support the theory of pectoral origin of this muscle. The second case was of a bilateral sternalis muscle, where the innervation supports the theory of SM originating from rectus abdominis. The aim of this paper is to raise awareness of SM amongst health care providers and educators of medicine. Knowledge of this muscle is important to health care providers involved in surgery and medical imaging of the anterior thoracic wall. As the occurrence of SM may be associated with the presence of mild cases of spinal anomalies such as spina bifida occulta, the authors suggest that researchers examine the pectoral region for SM when other spinal anomalies are present. This may help identify more cases of SM to promote further research in this area, including histological, developmental, and clinical studies. Clarification of the development of SM in relation to the axial skeleton is necessary to resolve the uncertainty around its nerve supply.

HUNG, L. Y.; LUCACIU, O. C. \& WONG, J. J. Volver al debate: músculo esternal. Int. J. Morphol., 30(1):322-329, 2012.

RESUMEN: El músculo esternal (ME) es una variante anatómica en la pared torácica anterior. Mientras que los sitios de fijación del ME estan acordados, la inervación y la función de este músculo no están bien establecida. Exploraciones cadavéricas y quirúrgicas han informado que el ME está inervado por los nervios pectorales o ramos anteriores de los nervios intercostales, o una combinación de ambos. El conocimiento del SE es relevante para los proveedores de atención de salud especializada de imágenes y / o cirugía de la pared torácica anterior. Este documento tiene como objetivo crear conciencia en la comunidad médica de la relevancia clínica de ME a través de dos reportes de caso y una breve revisión bibliográfica.

PALABRAS CLAVE: Músculos pectorales; Raquisquisis; Nervios pectorales; Nervios intercostales. 


\section{REFERENCES}

Arráez-Aybar, L. A.; Sobrado-Perez, J. \& Merida-Velasco, J. R. Left musculus sternalis. Clin. Anat., 16(4):350-4, 2003.

Bailey, P. M. \& Tzarnas, C. D. The sternalis muscle: a normal finding encountered during breast surgery. Plast. Reconstr. Surg., 103(4):1189-90, 1999.

Barlow, R. N. The sternalis muscle in American whites and negroes. Anat. Rec., 61(4):413-26, 1935.

Bradley, F. M.; Hoover, H. C. Jr.; Hulka, C. A.; Whitman, G. J.; McCarthy, K. A.; Hall, D. A.; Moore, R. \& Kopans, D. B. The sternalis muscle: an unusual normal finding seen on mammography. AJR Am. J. Roentgenol., 166(1):33-6, 1996.

Cunningham, D. J. The musculus sternalis. J. Anat. Physiol., 22(3):390.1-407, 1888.

Davis-Colley, J. N. C. Musculature of the Shoulder. In: Morris's Treatise On Anatomy. Morris, H. \& McMurrich, J. P. (Eds.). Philadelphia, P. Blakiston's Son \& Co., 1907. p.365.

Goktan, C.; Orguc, S.; Serter, S. \& Ovali, G. Y. Musculus sternalis: a normal but rare mammographic finding and magnetic resonance imaging demonstration. Breast J., 12(5):488-9, 2006.

Gupta, M. \& Harjeet. Bilateral sternales in relation to body of sternum. Nepal Med. Coll. J., 6(1):62-3, 2004.

Harish, K. \& Gopinath, K. S. Sternalis muscle: importance in surgery of the breast. Surg. Radiol. Anat., 25(3-4):311-4, 2003.

Harper, W. F. The Sternalis Muscle in the Anencephalous Foetus. J. Anat., 70(2):317-20, 1936.

Humphry, G. M. Lectures on the Varieties in the Muscles of Man. Br. Med. J., 1(651):693-6, 1873.

Jelev, L.; Georgiev, G. \& Surchev, L. The sternalis muscle in the Bulgarian population: classification of sternales. J. Anat., 199(3):359-63, 2001.

Jeng, H. \& Su, S. J. The sternalis muscle: an uncommon anatomical variant among Taiwanese. J. Anat., 193(2):287-8, 1998.

Kabay, B.; Akdogan, I.; Ozdemir, B. \& Adiguzel, E. The left sternalis muscle variation detected during mastectomy. Folia Morphol., 64(4):338-40, 2005.

Khan, U. D. Use of the rectus sternalis in augmentation mammoplasty: case report and literature search. Aesthetic Plast. Surg., 32(1):21-4, 2008.

Kida, M. Y.; Izumi, A. \& Tanaka, S. Sternalis muscle: topic for debate. Clin. Anat., 13(2):138-40, 2000.
Kida, M. Y. \& Kudoh, H. Innervation of the sternalis muscle accompanied by congenital partial absence of the pectoralis major muscle. Okajimas Folia Anat. Jpn., 67(6):449-55, 1991.

Kirk, T. S. Sternalis Muscle (in the Living). J. Anat., 59(2):192, 1925.

Kumar, H.; Rath, G.; Sharma, M.; Kohli, M. \& Rani, B. Bilateral sternalis with unusual left-sided presentation: a clinical perspective. Yonsei Med. J., 44(4):719-22, 2003.

Lamont, J. C. Notes on the Nervous Supply of the Musculus Sternalis. J. Anat. Physiol., 21(3):514-5, 1887.

Larsen, W. J. Human Embryology. Edinburgh, ChurchillLivingstone, 1997.

Lockhart, R. D. Muscles of Pectoral Region. In: Cunningham's Textbook of Anatomy. Brash, J.C. (Ed.). Edinburgh, R. \& R. Clark Limited, 1953. p.479.

Loukas, M.; Bowers, M. \& Hullett, J. Sternalis muscle: a mystery still. Folia Morphol., 63(2):147-9, 2004.

Motabagani, M. A.; Sonalla, A.; Abdel-Meguid, E. \& Bakheit, M. A. Morphological study of the uncommon rectus sterni muscle in German cadavers. East Afr. Med. J., 81(3):130-3, 2004.

Nuthakki, S.; Gross, M. \& Fessell, D. Sonography and helical computed tomography of the sternalis muscle. J. Ultrasound Med., 26(2):247-50, 2007.

O'Neill, M. N. \& Folan-Curran, J. Case report: bilateral sternalis muscles with a bilateral pectoralis major anomaly. J. Anat., 193(2):289-92, 1998.

Patten, C. J. Right Sternalis Muscle, Narrow and Spindle-shaped. J. Anat., 68(3):426, 1934.

Pérez, J.; Pérez-Gumá, J. E.; Correa, R.; Rivera, M.; Castro, A.; Cedeño, J.; López, M.; Nazario, L.; Otero, K.; Quiles, J. \& Sánchez, P. Breast mass or sternalis muscle? P. R. Health Sci. J., 27(2):185, 2008.

Pojchamarnwiputh, S.; Muttarak, M.; Na-Chiangmai, W. \& Chaiwun, B. Benign breast lesions mimicking carcinoma at mammography. Singapore Med. J., 48(10):958-68, 2007.

Rahman, N. A.; Das, S.; Maatoq Sulaiman, I.; Hlaing, K. P.; Haji Suhaimi, F.; Latiff, A. A. \& Othman, F. The sternalis muscle in cadavers: anatomical facts and clinical significance. Clin. Ter., 160(2):129-31, 2009.

Saeed, M.; Murshid, K. R.; Rufai, A. A.; Elsayed, S. E. \& Sadiq, M. S. Sternalis. An anatomic variant of chest wall musculature. Saudi Med. J., 23(10):1214-21, 2002. 
Salmons, S. Gray's Anatomy. Williams, P. L.; Bannister, L. H.; Berry, M. M.; Collins, P.; Dussek, J. E. \& Fergusson, M. W. J. (Eds.). New York, Churchill-Livingstone, 1995. p.838.

Sarikçıglu, L.; Demirel, B. M.; Oguz, N. \& Uçar, Y. Three sternalis muscles associated with abnormal attachments of the pectoralis major muscle. Anatomy, 2:67-71, 2008.

Schulman, M. R. \& Chun, J. K. The conjoined sternalis-pectoralis muscle flap in immediate tissue expander reconstruction after mastectomy. Ann. Plast. Surg., 55(6):672-5, 2005.

Scott-Conner, C. E. \& Al-Jurf, A. S. The sternalis muscle. Clin. Anat., 15(1):67-9, 2002.

Shen, C. L.; Chien, C. H. \& Lee, S. H. A Taiwanese with a pair of sternalis muscles. Kaibogaku Zasshi, 67(5):652-4, 1992.

Shepherd, F. J. Musculus Sternalis and its Nerve-Supply. J. Anat. Physiol., 23(2):303-7, 1889.

Shepherd, F. J. The Musculus Sternalis and its occurrence in (Human) Anencephalous Monsters. J. Anat. Physiol., 19(3):310.2-319, 1885.

Turner, W. On the Musculus Sternalis. J. Anat, Physiol., 1(2):246$378.25,1867$.

Vandeweyer, E. The sternalis muscle in head and neck reconstruction. Plast. Reconstr. Surg., 104(5):1578-9, 1999.

Wallace, D. Nerve Supply of Musculus Sternalis. J. Anat. Physiol., 21(1):153-4, 1886.

Windle, B. C. The Myology of the Anencephalous Foetus. J. Anat. Physiol., 27(3):348-53, 1893.

Young Lee, B.; Young Byun, J.; Hee Kim, H.; Sook Kim, H.; Mee Cho, S.; Hoon Lee, K.; Sup Song, K.; Soo Kim, B. \& Mun Lee, J. The sternalis muscles: incidence and imaging findings on MDCT. J. Thorac. Imaging, 21(3):179-83, 2006.

Zaher, W. A.; Darwish, H. H.; Abdalla, A, M. E.; Vohra, M. S. \& Khan, M. M. Sternalis: A Clinically Important Variation. Pak. J. Med. Sci. 25(2):325-8, 2009.
Correspondence to:

Laurie Hung

Canadian Memorial Chiropractic College

Toronto, Ontario

$\mathrm{M} 2 \mathrm{H}$ 3J1

CANADA

Email: laurieykhung@gmail.com

Received: 08-08-2011

Accepted: 13-10-2011 